\title{
Primary Kaposi's sarcoma of the heart in non-immunodeficient patient: case report and literature review
}

\author{
Eka Makharoblidze, Nana Goishvili, Maia Mchedlishvili and Mikheil Jangavadze* (1)
}

\begin{abstract}
We present a case of Kaposi's sarcoma (KS) of the heart in a 45-year-old non-immunodeficient woman with symptoms of pericardial effusion and cardiac tamponade. Computed Tomography (CT) coronary angiography and transesophageal echocardiography (TEE) showed a low-density tumorous mass (50 mm diameter) at the level of auricle of the right atrium spreading towards the superior vena cava, floating in the cavity of the right atrium. On histological examination, the tumor consisted of fibrovascular connective tissue with areas of necrosis and hemorrhage. Fibrous septae contained different sized thin walled capillary type blood vessels and lymphangioma-type vascular spaces. Vascular spaces were surrounded by extravasated erythrocytes, deposits of hemosiderin and sparse lymphoplasmacytoid infiltrates. On the periphery of tissue fragments and around vascular spaces, there was a cellular kaposiform proliferation of the spindled cells. Slit-like spaces between spindle cells contained erythrocytes. Nuclear pleomorphism of the spindled cells was minimal. Few mitotic figures were present. Spindle cells were Vimentin, CD34 and CD31 positive. More than $10 \%$ of spindled cells were Ki67 positive. This characteristic histology and immunohistochemistry is consistent with Kaposi's sarcoma. Patient has no history of other malignancies and no other primary tumor was detected. Patient also was negative for HIV infection. There are only 10 documented cases of primary Kaposi's sarcoma of the heart in non-immunodeficient patients reported in the current medical literature. Our report is the first case in which imaging, histology and immunohistochemistry data are available.
\end{abstract}

Keywords: Kaposi's sarcoma, Heart, Immunohistochemistry

\section{Background}

Primary tumors of the heart are very rare. Lifetime incidence ranges between 0.0017 to $0.02 \%$ [1]. Only about $6 \%$ of these tumors are malignant [2]. One third of them are angiosarcoma, but other malignant vascular tumors such as Kaposi's sarcoma and malignant epithelioid hemangioendothelioma are extremely rare. There are only 10 reported cases of primary cardiac Kaposi's sarcoma in non-immunodeficient persons in literature [3-11].

Kaposi's sarcoma (KS), which was described by Hungarian dermatologist Moritz Kaposi in 1872 [12], occurs mainly in skin, but visceral organs also get affected, especially in patients with AIDS [13, 14]. Nowadays, it is suggested, that KS is associated with

\footnotetext{
* Correspondence: mikheil.jangavadze@tsu.ge

Department of Pathology, Aleqsandre Natishvili Institute of Morphology, TSU, 2 Chiaureli Str, Tbilsi 0159, Georgia
}

superinfection by human herpesvirus 8 (HHV8, also known as Kaposi's sarcoma [KS]-associated herpesvirus) in immunodeficient patients [15-17]. However, in immunocompromised patients, subepicardial adipose tissue is more commonly involved than the myocardium or endocardium, compared to sporadic cases $[18,19]$.

Cardiac KS lesion mostly remains unrecognized during clinical and imaging investigation and is diagnosed only by pathologists. It is suspected that, before introduction of molecular techniques, such lesions have been confused with primary angiosarcoma of the heart, which is more common, than Kaposi's sarcoma [4]. Moreover, some authors suggest [20], that early reports of unusual cases of primary heart fibrosarcomas also can be classified as a Kaposis's sarcoma [21].

Here we present the case of a 45 year old nonimmunodeficient woman with primary Kaposi's sarcoma 
of the heart and a review of 10 cases, which we found in the medical literature through PubMed search using the search terms "Kaposi's sarcoma" AND "heart".

\section{Case presentation}

\section{Clinical history and radiologic findings}

45 year old female patient with symptoms of pericardial effusion and cardiac tamponade was referred to the clinic. Pericardiothentesis was performed immediately. Microbiological and cytological investigation of the pericardial fluid showed no evidence of an infection or malignancy. On the Computed Tomographic (CT) coronary angiography at the level of auricle of the right atrium, lowdensity tumorous mass $(50 \mathrm{~mm}$ in diameter) was found (Fig. 1a, b) (An additional movie file shows this in more detail [see Additional file 1]). No other abnormalities of cardiac structures were identified. TEE showed a tumor in the auricle of the right atrium extending towards superior vena cava. Free end of the tumor was floating in the cavity of right atrium (Fig. 1c, d) (Additional movie files show this in more detail [see Additional file 2 and Additional file 3]). Surgery was done 3 days after admission to the hospital. Non-complete surgical removal of the tumor was performed due to anatomic features of the tumor growth. The patient recovered and was discharged 9 days after the operation. On 10 month followup, the patient remained asymptomatic.

Paraffin embedded tissue samples from the pericardium and resected intracardiac tumor (auricle of the right atrium) were sent to our laboratory for reference.

\section{Histopathologic findings}

Tissue fragments had heterogeneous structures. One sample consisted of fibrovascular connective tissue with adipose tissue inclusions. Capillary and venous type blood vessels, with perivascular lymphoplasmocytoid infiltration were found in fibrose tissue. Two other tissue fragments generally were characterized by erythrocytes and "ghost" cells. Areas of necrosis and hemorrhage were surrounded by connective tissue septa (Fig. 2a). They contained variable-sized, thin-walled capillarytype blood vessels and lymphangioma-type vascular spaces, which were embedded in swollen collagen and hyaline matrix. There was a cellular kaposiform
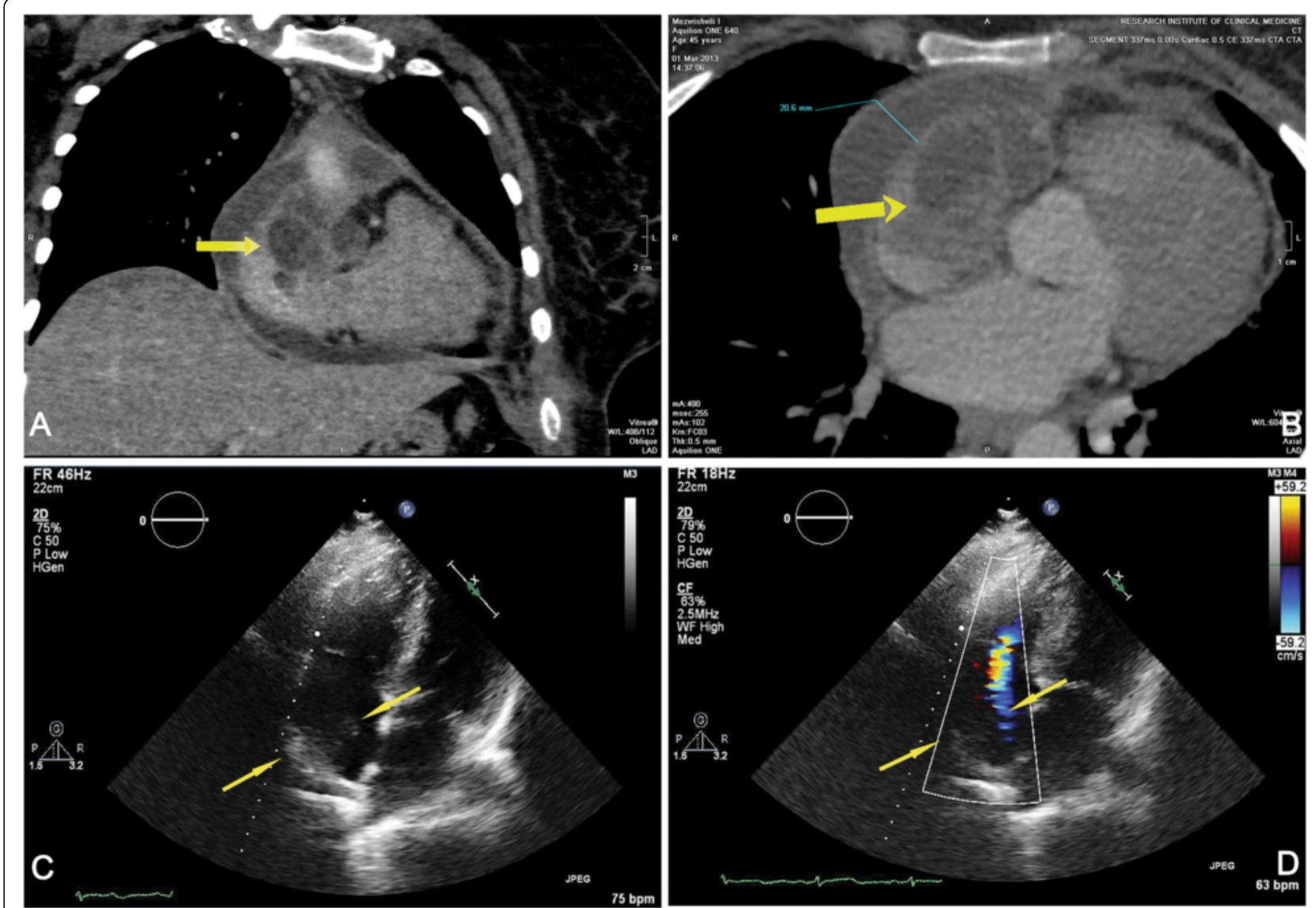

Fig. 1 a, b Computed Tomographic (CT) coronary angiography. Low-density tumorous mass (50 mm in diameter) at the level of auricle of the right atrium. c, d Transesophageal echocardiography. Tumor in the auricle of the right atrium, spreading toward superior vena cava 
proliferation of the spindled cells present focally, on the periphery and around vascular spaces. Slit-like spaces between spindle cells contained erythrocytes (Fig. 2b, c). In such areas, there were numerous extravasated erythrocytes, haemosiderophages and plasma cells. Nuclear pleomorphism of the spindled cells was minimal. Few mitotic figures were present (Fig. 2d).

Spindle cells were positive for vimentin, CD34 and CD31 (Fig. 3a, b, c, and d). Endothelial cell markers (CD34 and CD31) were also positive in necrotic "ghost" cells. Focally, some cells were $\alpha$-smooth muscle actin positive, which indicates presence of pericytes in cell proliferates (Fig. 3e). More than $10 \%$ of spindled cells were Ki67 positive (Fig. 3f).

Final diagnosis was primary Kaposi's sarcoma of the heart. The patient had no history of other malignancies and no other primary tumor was detected on CT or Magnetic Resonance Imaging (MRI). Patient was tested negative for HIV infection.

\section{Discussion}

Our paper presents a case of primary Kaposi's sarcoma of the heart in non-immunodeficient female patient (Table 1). Clinical presentation of pericardial effusion and cardiac tamponade was not indicative of malignancy. CT coronary angiography and TEE also failed to clarify disease entity. Such lesions may mimic vegetations and thrombi by their appearance and behavior.

In the available literature, we found 10 confirmed cases of primary Kaposi's sarcoma of the heart. Patients' age varied between 14 to 60 years with mean age of 41.9 . $70 \%$ of patients were more than 38 years old. Most tumors were localized in the right atrium [4-8], with two cases (including ours) of right atrial and pericardial involvement [10], one tumor was located in the left atrium [9] and one author described multiple lesions of the heart and pericardium [11]. In most cases tumor arose in the auricle of the right atrium. In these cases disease was diagnosed either postmortem (due to cardiac rupture) or during imaging procedure due to heart failure. Clinical presentation was almost similar in all cases.

Rarity of primary KS of the heart is not the only problem during histological evaluation of the tumor specimens. These lesions contain many necrotic areas, hemorrhages and thrombi, which complicates the tumor sampling. It is very important to perform a careful gross pathological examination and dissection (in case of postmortem study) or tumor tissue sampling (in case of surgical specimen). Pathologists have to promptly examine all suspicious tissues for histology. As shown by others [11] and in our case, main pathognomonic lesions, which give a clue for differential diagnosis, are located at the borders of the lesions. In addition, there are other malignant

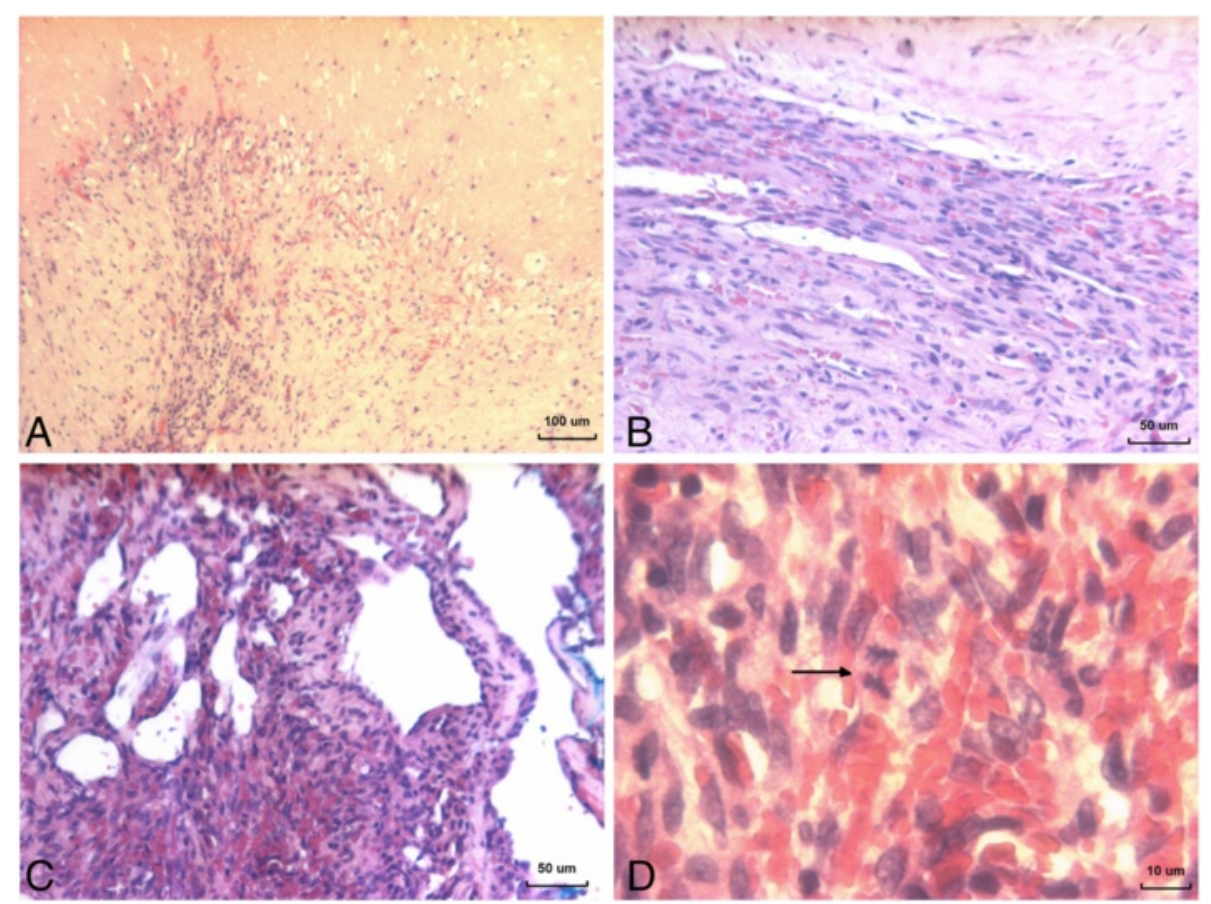

Fig. 2 a Areas of necrosis and hemorrhage surrounded by connective tissue septa. H\&E; (b) Kaposiform proliferation of the spindled cells with slit-like spaces. H\&E; (c) Slit-like spaces contains erythrocyte. H\&E; (d) Spindled cell with mitotic figure (arrow). H\&E 


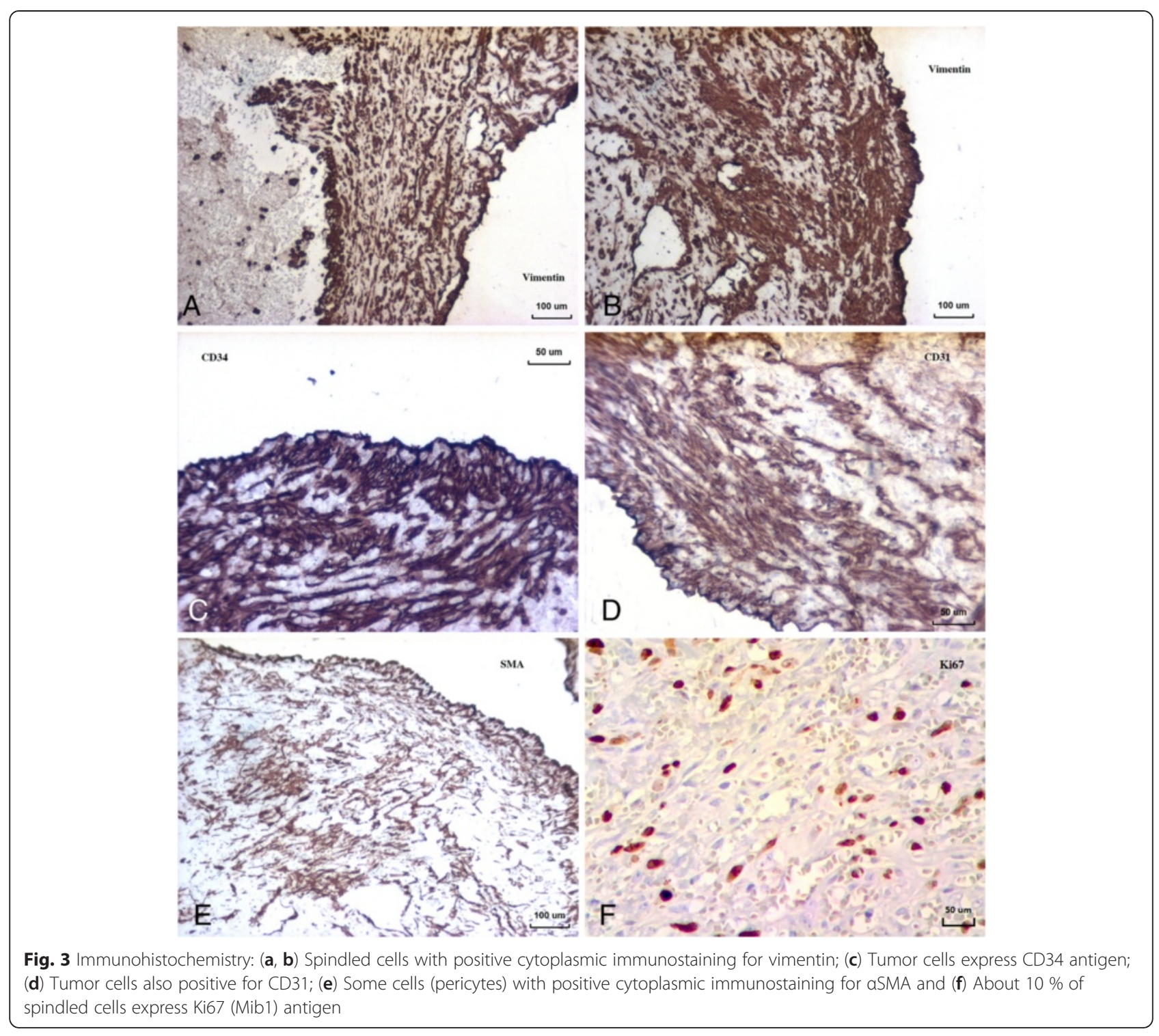

Table 1 Summaries of the 11 cases (including original) of the Primary Kaposi's sarcoma of the heart

\begin{tabular}{llllll}
\hline Case no. & Author & Year & Age & Sex & Site \\
\hline 1 & Choisser, R. M. et. al. [5] & 1939 & 26 & Male & Right atrium \\
2 & Choisser, R. M. et. al. [5] & 1939 & 30 & Male & Right atrium \\
3 & Da Cunha Motta, L. [10] & 1941 & 46 & Male & Right atrium, pericardium \\
4 & Aegerter, E. et al. [8] & 1942 & 60 & Male & Right atrium \\
5 & Contreras, R. [6] & 1957 & 43 & Male & Right atrium \\
6 & Gelfand, M. [7] & 1957 & 59 & Male & Right atrium \\
7 & Ayer, J. P., et al. [9] & 1962 & 38 & Female & Left atrium \\
8 & Rozegnal, W., et al. [3] & 1973 & Adult & Male & - \\
9 & Levison, D. A. et al. [4] & 1976 & 14 & Male & Right atrium \\
10 & Noohi, F., et al. [1 1] & 1997 & 58 & Male & Multiple lesion of the heart and pericardium \\
11 & Original case & 2013 & 45 & Female & Right atrium, pericardium \\
\hline
\end{tabular}


vascular tumors (spindle cell hemangioma $(\mathrm{SCH})$, angiosarcoma with predominant spindle cell morphology and Kaposhiform haemangioendothelioma) which clinically and histologically mimic Kaposi's sarcoma. As shown by other authors [22, 23] immunohistochemistry cannot clarify the diagnosis, because the molecular features of these tumors overlap. Although the authors noted [23], that the reactivity of CD34 is stronger in cases of skin Kaposi's sarcoma in comparison with a weak and focal reaction in angiosarcomas, in individual cases, like the rare tumors of the heart, the immunohistochemical investigation cannot discriminate angiosarcoma from Kaposi's sarcoma. This method only confirms vascular, endothelial origin of tumor cells and their proliferative capacity. In these cases, differential diagnosis basically lay on histological and cytological features of the tumor. Unlike our case, spindle cell hemangioma contains distinctive epithelioid cells containing vacuoles or intracytoplasmic lumens. The spindled areas of the $\mathrm{SCH}$ contain collapsed vessels, pericytes, and fibroblastic cells - all the elements of the vessel wall. Kaposhiform haemangioendothelioma was excluded base on clinical and histopathologic data. It's occurs nearly exclusively during the childhood. In addition, our case didn't contain areas with glomeruloid nests, epithelioid endothelial cells and hyaline globules, which are distinctive feature of the kaposhiform haemangioendothelioma. More poorly differentiated vascular tumor, such as angiosarcoma with predominant spindle cell morphology, exhibits more pleomorphism, and contains higher number mitotic cells, than Kaposi's sarcoma.

In some cases, exact type of tumor has no great impact on clinical outcome (lethal heart tamponade, postmortem diagnosis) but identification of the correct histologic type of the surgically resected tumor may be meaningful for consideration of adjuvant chemotherapy [22].

\section{Conclusion}

In summary, we report a rare case of primary KS of the heart, which showed overlapping clinical, radiological, histopathological and molecular features with other neoplastic and non-neoplastic lesions. Only histological and cytological features gave a clue about nature of the lesion. Immunohistochemistry in such cases plays a role of ancillary study and confirms the endothelial origin of tumor cells. It is helpful in cases when tumor mostly consists of diffuse proliferation areas mimicking fibrosarcomas $[21,20]$. We showed that adequate sampling for cardiac tumors has a great importance, because they contain large areas of necrosis, hemorrhage and thrombi complicating the precise recognition of tumorous tissues.

\section{Consent}

Written informed consent was obtained from the patient for publication of this Case Report and any accompanying images. A copy of the written consent is available for review by the Editor-in-Chief of this journal.

\section{Additional files}

Additional file 1: 3D Computer Tomography.

Additional file 2: Transesophageal echocardiography.

Additional file 3: Transoesophageal Echo-Doppler.

\section{Abbreviations}

KS: Kaposi's sarcoma; CT: Computed Tomography; TEE: Transesophageal echocardiography; HHV8: Human herpesvirus 8; aSMA: Alpha-Smooth Muscle Actin; MRI: Magnetic Resonance Imaging; SCH: Spindle cell hemangioma.

\section{Competing interests}

The authors declare that they have no competing interests.

\section{Authors' contributions}

EM, NG, MM performed the histological examination. EM, NG, MM and MJ have made substantial contributions to analysis and interpretation of patient data. MM analyzed and interpreted the patient data, drafted the manuscript and made the figures. All authors read and approved the final manuscript.

\section{Acknowledgements}

Authors are grateful to Mr. George Kurdgelashvili and Mrs. la Khakhutaishvili for manuscript revision.

Received: 6 May 2015 Accepted: 9 July 2015

Published online: 19 July 2015

\section{References}

1. Silverman NA. Primary cardiac tumors. Ann Surg. 1980;191(2):127-38.

2. Elbardissi AW, Dearani JA, Daly RC, Mullany CJ, Orszulak TA, Puga FJ, et al. Survival after resection of primary cardiac tumors: a 48-year experience. Circulation. 2008;118(14 Suppl):S7-15. doi: 10.1161/ CIRCULATIONAHA.107.783126.

3. Rozegnal W, Borkowski P, Stawarz B. A case of primary tumor of the heart (angiosarcoma-Kaposi's sarcoma) with fatal outcome due to spontaneous rupture and cardiac tamponade. Kardiol Pol. 1973;16(4):323-6.

4. Levison DA, Semple P. Primary cardiac Kaposi's sarcoma. Thorax. 1976;31(5):595-600.

5. Choisser RM, Ramsey EM. Angioreticuloendothelioma (Kaposi's disease) of the heart. Am J Pathol. 1939;15(2):155-78.5.

6. Contreras R. Primary Kaposi angiosarcoma of the heart; review of literature \& description of the 6th case. Arch Inst Cardiol Mex. 1957;27(4):463-79.

7. Gelfand M. Kaposi's haemangiosarcoma of the heart. Br Heart J. 1957;19(2):290-2.

8. Aegerter E, Peale A. Kaposi's sarcoma. A critical survey. Arch Pathol. 1942;34(413-422):5.

9. Ayer JP, Paul O, Capps RB. Clinical pathologic conference. Am Heart J. 1962;63:566-72.

10. Da Cunha ML. Hemangio reticulo-endothelioma. Ann Fac Med Sao Paulo. 1941;17:627-49.

11. Noohi F, Moshiri M, Hashemi H, Shariat R, Forood A. Primary cardiac Kaposi's sarcoma. Ann Saudi Med. 1997;17(3):357-9.

12. Kaposi M. Idiopathic multiple pigmented sarcoma of the skin. CA Cancer J Clin. 1982;32(6):342-7.

13. Pantanowitz L, Dezube BJ. Kaposi sarcoma in unusual locations. BMC Cancer. 2008:8:190. doi:10.1186/1471-2407-8-190.

14. Antman K, Chang Y. Kaposi's sarcoma. N Engl J Med. 2000;342(14):1027-38. doi:10.1056/NEJM200004063421407.

15. Emond JP, Marcelin AG, Dorent R, Milliancourt C, Dupin N, Frances C, et al. Kaposi's sarcoma associated with previous human herpesvirus 8 infection in heart transplant recipients. J Clin Microbiol. 2002;40(6):2217-9. 
16. Collart F, Kerbaul F, Damaj G, Zandotti C, Vey N, Mesana T, et al. Visceral Kaposi's sarcoma associated with human herpesvirus 8 seroconversion in a heart transplant recipient. Transplant Proc. 2004;36(10):3173-4 doi:10.1016/j.transproceed.2004.10.058

17. Concato C, Diociaiuti A, Parisi F, Giraldi L, Ciasulli A, Menichella D, et al. Human herpesvirus-8 serology in pediatric organ transplantation. Transplant Proc. 2008;40(10):3683-4. doi:10.1016/j.transproceed.2008.06.085.

18. Cammarosano C, Lewis W. Cardiac lesions in acquired immune deficiency syndrome (AIDS). J Am Coll Cardiol. 1985;5(3):703-6.

19. Templeton AC. Studies in Kaposi's sarcoma. Postmortem findings and disease patterns in women. Cancer. 1972;30(3):854-67.

20. Weller JGL. The clinical aspects of cardiac involvement (right auricular tumor) in idiopathic hemorrhagic sarcoma (Kaposi's disease). Ann Intern Med. 1940;14:314.

21. Raw N. Primary tumour of right auricle of heart, rupture of inferior vena cava. Br Med J. 1898;2(1974):1335.

22. Pitt M, Rooney S, Murray RG. An unusual case of pericardial constriction. Br J Cardiol. 2002;9:615-6.

23. Kodetova D, Dorazilova $V$, Simek $S$. An unusual vascular tumor of the pericardium resembling Kaposi's sarcoma. Cesk Patol. 1995;31(3):79-83.

\section{Submit your next manuscript to BioMed Central and take full advantage of:}

- Convenient online submission

- Thorough peer review

- No space constraints or color figure charges

- Immediate publication on acceptance

- Inclusion in PubMed, CAS, Scopus and Google Scholar

- Research which is freely available for redistribution 